\title{
Pleural Fluid and Serum Leptin Levels in the Differential Diagnosis of Pleurisy
}

\author{
Aybüke Kekeçoğlu', Burcu Karaokur ${ }^{1}$, Sibel Yurt ${ }^{1}$, Levent Dalar², \\ Ayşe Filiz Koşar ${ }^{1}$
}

${ }^{1}$ Department of Chest Diseases, Yedikule Pulmonary Diseases and Thoracic Surgery Education and Research Hospital, İstanbul ${ }^{2}$ Department of Pulmonary Medicine, İstanbul Bilim University Faculty of Medicine, İstanbul

\begin{abstract}
Objective: To investigate the diagnostic value of serum and pleural fluid leptin levels in the differentiation between transudate and exudate, tuberculosis and nontuberculosis pleural effusion, and different diseases in treatment-naïve patient groups with different diseases that present with pleural fluid (pleural fluid due to tuberculosis, malignant pleural fluid, transudative pleural fluid and parepneumonic pleural fluid).
\end{abstract}

Methods: The study comprised a total of 78 consecutive cases (32 females and 46 males). The cases were assigned to two groups as transudative and exudative pleural effusion according to Light criteria. Cases with exudative fluid were divided into three groups; tuberculosis (TB), nonspecific (parapneumonic) and malignant pleural fluid. Weight and height were measured in all patients and body mass index (BMI) was calculated. Pleural fluid and serum leptin levels were measured in all disease groups and their diagnostic value was investigated.

Results: Leptin levels were measured in the serum and pleural fluids and adenosine deaminase (ADA) level was studied in the pleural fluids of the patients. No statistically significant difference was determined between leptin levels of patients that were grouped according to their diagnosis $(p<0.05)$. There was also no significant difference between transudate and exudates in terms of leptin and ADA levels. When the patients were grouped as TB and non-TB, no difference was found between the groups in terms of serum and pleural fluid leptin levels, whereas pleural ADA concentration was significantly higher in the tuberculosis group in comparison to the other group. A weak positive correlation was determined between body mass index and serum and pleural leptin levels $(r=0.39$ and $r=0.42$ respectively, $p<0.001)$.

Conclusion: Nevertheless the present study included a limited number of patients, serum and pleural leptin levels remained inadequate both in the differentiation between transudates and exudates and in achieving an etiological diagnosis. Despite the results suggesting a significant decrement in tuberculosis pleurisy, it is clear that further studies are needed on this subject.

Keywords: Adenosine deaminase, leptin, pleura, tuberculosis

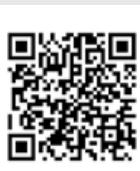

Received date: 24.09 .2013

Accepted date: 07.12.2013

\section{Address for correspondence}

Levent Dalar, Department of Pulmonary Medicine,

İstanbul Bilim University Faculty of Medicine,

İstanbul, Turkey

E-mail: leventdalar@yahoo.com

(C) Copyright 2014 Turkish Respiratory Society (TRS) DOI: 10.5152/ejp.2014.91886

-Available online at www.eurasianjpulmonol.com

\section{INTRODUCTION}

Pleural fluid is frequently encountered in the clinics and sometimes recognized as a compelling problem since its aetiology cannot always be identified easily.

Once the presence of pleural fluid is determined in a patient, a difficult process begins including a range of analysis to determine the aetiology. However, diagnosis could not be made in $15-20 \%$ of the cases even if all diagnostic procedures have been implemented (1).

An accurate and rapid fluid analysis is required for the exploration of patients with pleural fluid. For this purpose, primarily transudates should be differentiated from exudates by thoracentesis. While transudative pleural fluid does not pose a significant etiological problem, exudates may sometimes require many invasive and expensive analyses for differential diagnosis. Diagnostic difficulties necessitate the investigation of various new markers in pleural fluid. 
Leptin is a polypeptide hormone synthesized and secreted by adipose-specific ob gene. It is known that leptin has an important role in natural and acquired immunity. Increase in leptin levels during infection/inflammation suggests that it is an important factor in host response to inflammation. As a proinflammatory agent, leptin is increased in chronic diseases causing inflammation. Besides, along with the decrease in adipose tissue in case of cachexia secondary to chronic disease, leptin secretion from adipose tissue is expected to decrease. Therefore, leptin levels may be different in different stages of inflammation (2-4). Based on this information, a few studies have been conducted in the recent years on the use of leptin levels to determine the aetiology of pleural fluid (5-9).

The present study aimed to investigate the diagnostic value of serum and pleural fluid leptin levels in the differentiation between transudate and exudate fluids, in tuberculosis (TB) and non-tuberculosis disease groups, and different diseases in treatment-naïve patient groups that were admitted with pleural fluid (TB-related pleural fluid, malignant pleural fluid, transudative pleural fluid and parapneumonic pleural fluid), as well as to compare the diagnostic value of leptin and pleural fluid adenosine deaminase (ADA) concentrations in TB and non-tuberculosis disease groups.

\section{METHODS}

The present study was carried out between June 2009 and September 2009 in Yedikule Chest Diseases and Thoracic Surgery Training and Research Hospital, $6^{\text {th }}$ Clinic, which is a tertiary chest diseases clinic, and approval of the local ethics committee was obtained.

\section{Cases}

Consecutive 78 cases ( 46 males, 32 females) were included in the present study. All cases were informed about the study and they were made to read and sign informed voluntary consent forms. The cases included in the study were assigned to transudative or exudative pleural fluid groups according to the Light criteria. Exudative fluid group was divided into three subgroups; TB, nonspecific (parapneumonic) and malignant pleural fluid. Group 1:Transudative pleural fluid (18 cases), Group 2: Tuberculosis-related pleural fluid (21 cas-

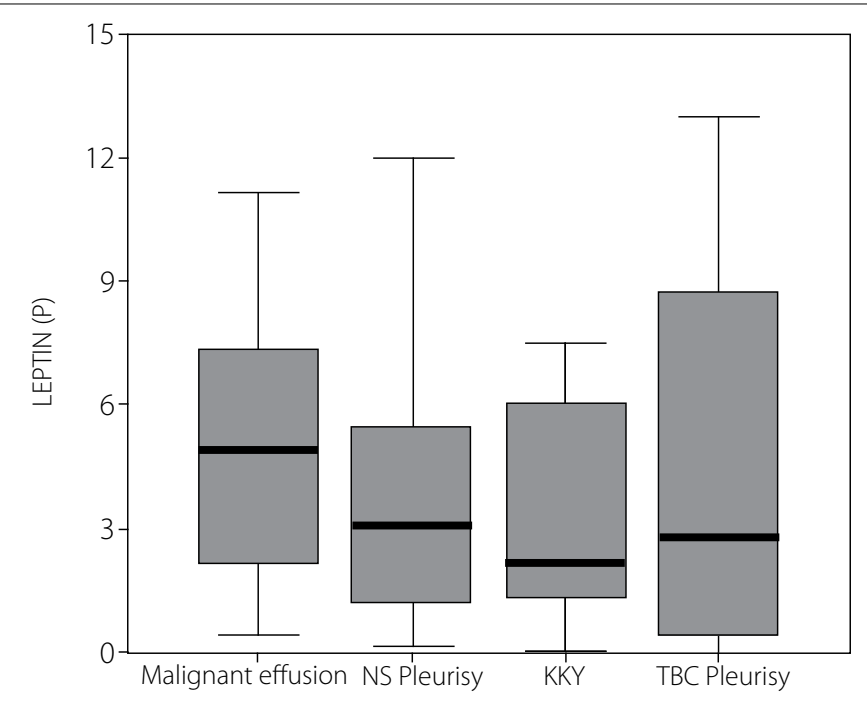

Figure 1. Distribution of pleural fluid leptin levels according to disease groups es), Group 3: Nonspecific pleural fluid (20 cases), Group 4: Malignant pleural fluid (19 cases).

After anamnesis and physical examinations, postero-anterior chest $x$-rays of the patients were taken. Blood samples were obtained from forearm veins for routine analyses including complete blood count, erythrocyte sedimentation rate, C-reactive protein (CRP), biochemical analyses, and bleeding and clotting parameters.

\section{Pleural Fluid Sampling and Storage of Samples}

Pleural fluid, which was obtained by thoracentesis, was sent to the microbiology and biochemistry laboratories for cell count and leukocyte formula analyses, as well as lactate dehydrogenase (LDH), protein, glucose, albumin, and ADA concentrations. Differentiation between transudate and exudate pleural fluids was made according to the "Light criteria". In addition, 3 cc of pleural fluid and fasting blood was obtained in the morning to study leptin levels and centrifuged at $4000 \mathrm{rpm} / \mathrm{min}$ for 4 minutes and then $1 \mathrm{cc}$ of the sample was taken from the supernatant, was put into eppendorf tubes, and stored at $+4^{\circ} \mathrm{C}$ until the day of analysis.

While no further analysis was performed for transudative fluids, cases that had exudative fluid with lymphocyte predominance underwent closed pleural biopsy via Ramel needle.

\section{Analysis for Leptin Levels}

Leptin levels were measured both in the serum and pleural fluids of all patients. Serum leptin level was studied by ELISA method using EASIA (Biosource Europe S.A, Nivelles, Belgium) kits.

\section{Statistical Analysis}

Data were analysed by SPSS for Windows 10.0 (Chicago, ABD) statistical package program, whereas comparisons were made by ANOVA and Tukey HSD, Kruskal-Wallis, Covariance analysis, Student's t-test, and Mann-Whitney $U$ test. While Pearson correlation method was used for the correlation analysis, ROC analysis was used for the differentiation between transudate and exudate fluids and $p<0.05$ was considered significant.

\section{RESULTS}

Of the 78 patients included in the study, 46 (58.9\%) were male and 32 (41.1\%) were female. Ages of the participants ranged between 15 and 85 years, with a mean age of 51.7 years. The mean age of the patients in disease groups were as follows; $58.8 \pm 14.6$ years for malignant fluid group, $52.4 \pm 16.7$ years for nonspecific fluid group, $67.7 \pm 15.1$ years for transudative fluid group, and $31.2 \pm 13.9$ years in TB group. The mean age of the patients in the transudative fluid group was significantly higher as compared to all other groups $(p<0.001)$, whereas the mean age was significantly lower in the TB group $(p<0.001)$.

Of the 78 patients included in the study, 18 (23\%) had transudative fluid and $60(77 \%)$ had exudative fluid. Mean pleural fluid and serum leptin levels were $6.13 \mathrm{ng} / \mathrm{mL}$ and $7.87 \mathrm{ng} / \mathrm{mL}$, respectively for the transudate group, whereas the corresponding figures were $5.45 \mathrm{ng} /$ $\mathrm{mL}$ and $7.65 \mathrm{ng} / \mathrm{mL}$, respectively for the exudate group. No significant difference was found between the groups in terms of serum and pleural fluid leptin levels ( $p>0.05$ ) (Table 1). Figures 1 and 2 illustrate the distribution of pleural and serum leptin levels among disease groups. 
The mean pleural fluid and serum leptin levels in the disease groups were as follows: $6.96 \mathrm{ng} / \mathrm{mL}$ and $10.62 \mathrm{ng} / \mathrm{mL}$, respectively in the malignant fluid group; $5.15 \mathrm{ng} / \mathrm{mL}$ and $8.62 \mathrm{ng} / \mathrm{mL}$, respectively in the nonspecific fluid group; $6.13 \mathrm{ng} / \mathrm{mL}$ and $7.87 \mathrm{ng} / \mathrm{mL}$, respectively in the transudate group; and $4.37 \mathrm{ng} / \mathrm{mL}$ and $4.02 \mathrm{ng} / \mathrm{mL}$, respectively in the TB pleurisy group. No significant difference was determined between the groups in terms of pleural fluid and serum leptin levels ( $p>0.05$ ) (Table 2).

When the cases were divided into two main groups as TB and nonTB and were compared in terms of leptin and ADA concentrations, no difference was determined between the groups in terms of leptin levels ( $p>0.05$ ), whereas ADA concentration was significantly higher in the TB group $(p=0.031)$ (Table 3$)$.

\section{DISCUSSION}

Pleural fluid, which is described as abnormal fluid collection in the pleural space, may develop due to various aetiologies. After clinical and radiological detection of pleural fluid, a difficult process begins including a range of analyses for the aetiology. Approximately $15-20 \%$ of patients remain undiagnosed and some cases are diagnosed only clinically, even if all diagnostic analyses including imaging techniques, cellular, microbiological and biochemical analysis of fluid, cytological examination, and closed or open biopsy have been performed (1). Diagnostic difficulties necessitate the investigation of various new markers in pleural fluid.

Leptin, which is an adipocyte-originated hormone, plays an important role in nutrition and energy homeostasis and shows appetite-de-

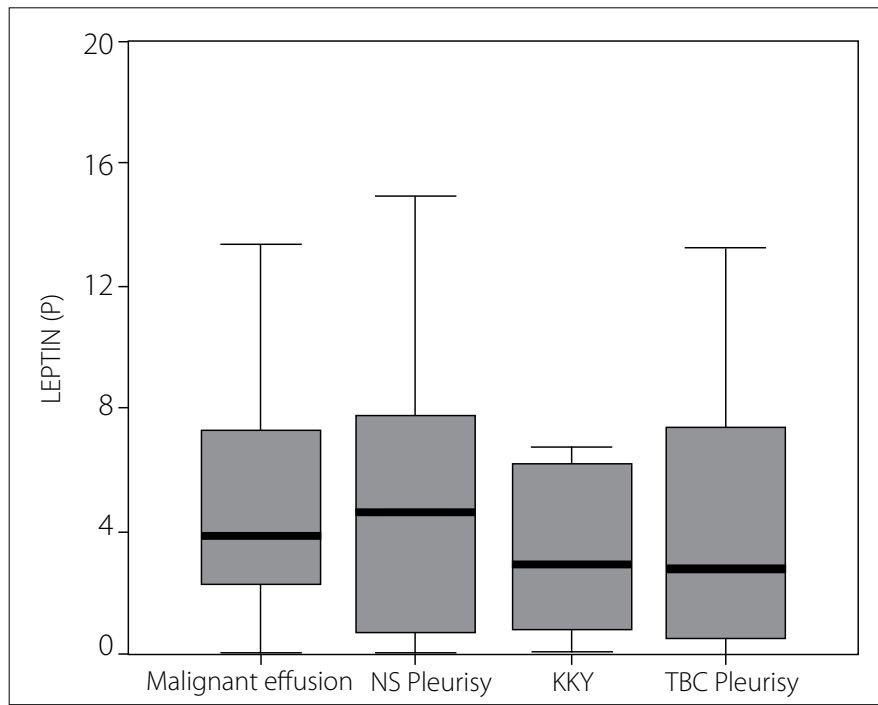

Figure 2. Distribution of serum leptin levels according to disease groups creasing and energy consumption-enhancing effects by influencing hypothalamus via negative feed-back. Leptin deficiency or resistance results in obesity, diabetes and infertility in human. Main effects of leptin on many systems such as anti-obesity, reproductive, haematopoiesis, angiogenesis, blood pressure, growth, bone volume, lymphoid organ homeostasis, and T-lymphocyte systems have been largely demonstrated (2-4).

Leptin may also be classified as a proinflammatory cytokine due to its structural similarity with cytokines, and it is known to have an important role in natural and acquired immunity due to this effect. It is thought that increase in leptin levels during inflammation/infection is an important factor in host response to inflammation. It is believed that this acute phase response of the host is effective also in anorexia that is encountered over the course of infections. As a proinflammatory agent, leptin levels are increased in case of chronic disease causing inflammation. Besides, leptin secretion from adipose tissue is expected to decrease along with the decrease in adipose tissue in case of cachexia secondary to chronic disease. Therefore, leptin levels may be different in different phases of inflammation (10-12).

Two opposite mechanisms may play a role in leptin levels in tuberculosis. While fat loss causes a decrease in leptin levels, host response in case of inflammation may cause increase in leptin. If leptin levels are increased in tuberculosis patients, appetite and food intake may

Table 1. Comparison of mean pleural fluid and serum leptin levels between transudative and exudative pleural fluid groups

\begin{tabular}{|l|c|c|c|c|c|}
\hline & \multicolumn{2}{|c|}{ Transudate } & \multicolumn{2}{c|}{ Exudate } & \\
& Mean & SD & Mean & SD & P \\
\hline Leptin P & 6.13 & 11.08 & 5.45 & 6.23 & .730 \\
\hline Leptin S & 7.87 & 14.67 & 7.65 & 14.14 & .963 \\
\hline
\end{tabular}

Leptin P: Pleural fluid leptin level; Leptin S: serum leptin level; SD: standard deviation

Table 3. Comparison of pleural fluid and serum leptin levels, ADA and BMI values between TB and non-TB groups

\begin{tabular}{|l|c|c|c|c|c|}
\hline & \multicolumn{2}{|c|}{ Non-TB } & \multicolumn{2}{c|}{ TB } & \\
& Mean & SD & Mean & SD & P \\
\hline Leptin P & 6.06 & 8.36 & 4.36 & 4.58 & .367 \\
Leptin S & 9.05 & 16.23 & 4.02 & 3.98 & .362 \\
ADA & 54.06 & 29.94 & 71.71 & 28.88 & .031 \\
BMI & 24.65 & 5.23 & 21.66 & 2.84 & .015 \\
\hline
\end{tabular}

ADA: Adenosine deaminase; Leptin P: pleural leptin level; Leptin S: serum leptin level; SD: standard deviation; TB: Tuberculosis; BMI: body mass index

Table 2. Pleural fluid and serum leptin levels in disease groups

\begin{tabular}{|l|c|c|c|c|c|c|c|c|c|}
\hline & \multicolumn{2}{|c|}{ Malignant fluid } & \multicolumn{2}{c|}{ Nonspecific fluid } & \multicolumn{2}{c|}{ Transudate } & \multicolumn{2}{c|}{ TB pleurisy } \\
& Mean & SD & Mean & SD & Mean & SD & Mean & SD & P \\
\hline Leptin P & 6.96 & 8.18 & 5.15 & 5.59 & 6.13 & 11.08 & 4.37 & 4.58 & .729 \\
\hline Leptin S & 10.62 & 18.13 & 8.62 & 16.39 & 7.87 & 14.67 & 4.02 & 3.98 & .519 \\
\hline
\end{tabular}


theoretically be suppressed and this may be one of the underlying mechanisms of weight loss. On the contrary, if leptin is decreased in tuberculosis patients, immunity is suppressed and outcome may worsen (13-16). Based on this information, the use of leptin levels in inflammatory disease have started to be examined in the studies published in the recent years.

In a study conducted in Turkey, comprising a total of 45 patients, pleural fluid and serum leptin levels and pleural fluid/serum leptin ratio were evaluated and patients were assigned to two different groups as TB and non-TB. Pleural fluid and serum leptin levels were found to be significantly lower but pleural fluid ADA activity, pleural fluid /serum ADA activity ratio were found to be significantly higher in TB pleurisy group as compared to non-TB group (5). In another study, Prabha et al. (6) examined a total of 40 cases, of which 20 had TB pleurisy and 20 had non-TB pleurisy, and found that pleural fluid leptin levels were significantly lower in the TB group as compared to the non-TB group $(p<0.01)$.

Whereas it has been concluded that weight loss in tuberculosis do not result from increased leptin production but rather the decrease in body fat mass pioneers low plasma leptin levels, a significant increase is observed in plasma leptin levels during anti-tuberculosis therapy. Likewise, it was determined that body fat ratio significantly increases with treatment and there is a strong positive correlation between leptin and body fat ratio (8).

Büyükoğlan et al. (9) measured serum leptin and tumour necrosis factor-alpha (TNF- $a$ ) concentrations before and after anti-tuberculosis therapy in patients with active tuberculosis and compared them with that of the control group; they suggested that leptin levels were suppressed in tuberculosis patients and low leptin levels contributed to an increase in susceptibility against infection and development of sequels.

In the present study, when the patients were assigned to two main groups as TB and non-TB, and leptin, ADA and other parameters were compared between these two groups, no difference was found in terms of pleural fluid and serum leptin levels, but ADA and erythrocyte sedimentation rate were found to be significantly higher in the tuberculosis group ( $p<0.05$ and $p<0.001$, respectively). Age, weight and body mass index (BMI) were significantly lower in the tuberculosis group in comparison to the non-tuberculosis group $(p<0.05$, $p<0.01$ and $p<0.001$, respectively). Likewise, Lee et al. (10) included a total of 23 patients, of whom 9 had tuberculosis pleurisy, 6 had parapneumonic pleurisy and 8 had malignant pleurisy, and determined no significant difference between three groups in terms of pleural fluid and serum leptin levels.

\section{CONCLUSION}

No statistically significant difference was determined between pleurisy cases, which were divided into groups according to different etiological factors, in terms of pleural fluid and serum leptin levels $(p<0.05)$. Likewise, no significant difference was determined in terms of leptin and ADA concentrations measured for the differentiation between transudative and exudative fluids. When the cases were divided into TB and non-TB groups, no significant difference was determined between the groups in terms of serum and pleural leptin levels, but pleural fluid ADA concentration was significantly higher in the TB group as compared to the non-TB group.
While the number of cases was limited in the present study, it was observed that serum and pleural leptin levels are not adequate either in the differentiation between transudate and exudate or in achieving an etiological diagnosis. It is clear that new studies are needed on this subject despite the significant decrement in tuberculosis pleurisy.

Ethics Committee Approval: Ethics committee approval was received for this study from the ethics committee of Yedikule Chest Diseases and Chest Surgery Training and Research Hospital.

Informed Consent: Written informed consent was obtained from patients who participated in this study.

Peer-review: Externally peer-reviewed.

Author Contributions: Concept - A.K., F.K.; Design - A.K., F.K., S.Y.; Supervision - F.K., L.D., Resources - B.K., L.D.; Materials - A.K.; Data Collection and/or Processing - A.K, B.K, S.Y.; Analysis and/or Interpretation - A.K., F.K., L.D.; Literature Review - A.K., L.D., B.O.; Writer - A.K., L.D.; Critical Review - F.K., L.D.

Conflict of Interest: No conflict of interest was declared by the authors.

Financial Disclosure: The authors declared that this study has received no financial support.

\section{REFERENCES}

1. Light RW. Pleural effusions. Med Clin North Am 2011; 95: 1055-70. [CrossRef]

2. Meier CA, Bobbioni E, Gabay C, Assimacopoulos-Jeannet F, Golay A, Dayer JM. IL-1 receptor antagonist serum levels are increased in human obesity: a possible link to the resistance to leptin? J Clin Endocrinol Metab 2002; 87: 1184-8. [CrossRef]

3. Dattani MT. Tests in pediatric endocrinology and normal values. In: Brook GDC, Hindmarsh PC (Eds). Clinical pediatric endocrinology. 4th ed. London: Blackwell Science Ltd; 2001.p.467-95.

4. van Crevel R, Karyadi E, Netea MG, Verhoef $\mathrm{H}$, Nelwan $\mathrm{RH}$, West $\mathrm{CE}$, et al. Decreased plasma leptin concentrations in tuberculosis patients are associated with wasting and inflammation. J Clin Endocrinol Metab 2002; 87: 758-63. [CrossRef]

5. Celik G, Kaya A, Poyraz B, Ciledag A, Elhan AH, Oktem A, et al. Diagnostic value of leptin in tuberculous pleural effusions. Int J Clin Pract 2006; 60: 1437-42. [CrossRef]

6. Prabha C, Supriya P, Das SD, Sukumar B, Balaji S. Leptin response in patients with tuberculous pleuritis. Indian J Med Res 2008; 128: 721-7.

7. Lee GH, Proenca R, Montez JM, Carroll KM, Darvishzadeh JG, Lee Jl, et al. Abnormal splicing of the leptin receptor in diabetic mice. Nature 1996; 379:632-5. [CrossRef]

8. Friedman JM. Leptin, leptin receptors, and the control of body weight Nutrition 1998; 56: 38-46.

9. Buyukoglan H, Gulmez I, Kelestimur F, Kart L, Oymak FS, Demir R, et al. Leptin levels in various manifestations of pulmonary tuberculosis. Mediators Inflamm 2007; 2007: 64859.

10. Lee HK, Hur WJ, Lee SS. Pleural fluid leptin level for the differential diagnosis of pleural effusion. Eur Respir J 2006; 28: 343S.

11. Siegmund B, Lehr HA, Fantuzzi G. Leptin: a pivotal mediator of intestinal inflammation in mice. Gastroenterology 2002; 122: 2011-25. [CrossRef]

12. Fujita $Y$, Murakami $M$, Ogawa $Y$, Masuzaki $H$, Tanaka $M$, Ozaki $S$, et al. Leptin inhibits stress-induced apoptosis of T lymphocytes. Clin Exp Immunol 2002; 128: 21-6. [CrossRef]

13. Juge-Aubry CE, Meier CA. Immunomodulatory actions of leptin. Mol Cell Endocrinol 2002; 194: 1-7. [CrossRef]

14. Schwenk A, Hodgson L, Rayner CF, Griffin GE, Macallan DC. Leptin and energy metabolism in pulmonary tuberculosis. Am J Clin Nutr 2003; 77: 392-8.

15. Prins JB, O.Rahilly $\mathrm{S}$. Regulation of adipose cell number in man. Clin Sci (Lond) 1997; 92: 3-11.

16. Zhang Y, Proenca R, Maffei M, Barone M, Leopold L, Friedman JM. Positional cloning of the mouse obese gene and its human homologue. Nature 1994; 372: 425-32. [CrossRef] 